\title{
Desafios da formação em enfermagem no Brasil: proposta curricular da EEUSP para o bacharelado em enfermagem*
}

\author{
CHALLENGES IN NURSING EDUCATION IN BRAZIL: BACCALAUREATE CURRICULAR \\ PROPOSAL OF THE SCHOOL OF NURSING OF SAO PAULO UNIVERSITY
}

\section{DESAFÍOS PARA LA FORMACIÓN EN ENFERMERÍA EN BRASIL: PROPUESTA CURRICULAR PARA EL BACHILLERATO DE LA FACULTAD DE ENFERMERÍA DE LA UNIVERSIDAD DE SÃO PAULO}

\section{Maria Amélia de Campos Oliveira', Maria De Lá ó Ramallo Veríssimo², Vilanice de Araújo Püschel ${ }^{3}$, Maria Luiza Gonzalez Riesco ${ }^{4}$}

\footnotetext{
* A proposta curricular vem sendo construí da pelo Grupo de Apoio Pedagógico da Escola de Enfermagem da USP - GAP sob a coordenação das Professoras Doutoras Maria Luiza Gonzalez Riesco e Vilanice da Araújo Püschel, com a participação de docentes e discentes da EEUSP e representantes do Hospital Universitário da USP.

1 Enfermeira. Presidente da Comissão de Graduação da Escola de Enfermagem, Universidade de São Paulo (EEUSP). São Paulo, SP, Brasil.

macampos@usp.br

2 Enfermeira. Coordenadora do Curso de

Bacharelado em

Enfermagem da

Escola de Enfermagem, Universidade de São Paulo (EEUSP). São Paulo, SP, Brasil. mdlorver@usp.br

3 Enfermeira. Coordenadora do GAP. da Escola de Enfermagem, Universidade de São Paulo (EEUSP). São Paulo, SP, Brasil. vilanice@usp.br

4 Enfermeira. Membro do GAP. Vice-presidente da Comissão de Graduação da Escola de Enfermagem, Universidade de São Paulo (EEUSP) (2002-2006). Coordenadora do GAP (2004-2007). São Paulo, SP, Brasil. riesco@usp.br
}

\section{RESUMO}

O atual currículo do curso de graduação em Enfermagem da Escola de Enfermagem da USP está sendo reformulado e sua implantação está prevista para 2009. Este artigo tem por objetivo apresentar, em linhas gerais, o novo currículo do curso de graduação emEnfermagem daEEUSP. A estrutura proposta está dividida em três ciclos: Básico (1.500 horas), Intermediário (1.500 horas) e Complementar (1.000 horas), com carga horária total de 4.000 horas, ministrada em oito semestres letivos. A mudança visa a aumentar a integração entre as disciplinas e os departamentos, a autonomia do estudante e adotar a formação para o Sistema Único de Saúde como orientação geral do currículo. O novo currículo está voltado à formação da enfermeira generalista, com competência técnica, científica e ético-política para prestar cuidados de enfermagem a indivíduos, famílias e grupos sociais.

\section{DESCRITORES}

Enfermagem.

Ensino.

Currículo.

\section{ABSTRACT}

The School of Nursing of the University of Sao Paulo is involved in a process to change the Baccalaureate curriculum, and its implementation is planned to happen in 2009. This is a presentation of the main guidelines of the new curriculum. It is structured in three cycles: Basic (1.500h), Intermediate (1.500) and Final (1.000h), with $4.000 \mathrm{~h}$ in total, in eight semesters. The aim of the change is to increase de integration among its courses and departments, to promote the autonomy of the student and to adopt as guidelines the principles of the Unified Health Care System in Brazil. The profile aimed is of a general practitioner in nursing, with technical, scientific, ethical and political competencies to provide nursing care to individuals, families and social groups.

\section{KEY WORDS}

Nursing.

Teaching.

Curriculum.

\section{RESUMEN}

El actual currículo de bachillerato de la Facultad de Enfermería de la Universidad de São Paulo está siendo reformulado y su implantación está prevista para el 2009. El objetivo de este trabajo fue presentar, en líneas generales, el nuevo currículo de bachillerato en Enfermería. La estructura del nuevo currículo se divide en tres ciclos: Básico (1.500h), Intermedio (1.500h) y Complementar (1.000), totalizando $4.000 \mathrm{~h}$, las que son suministradas en ocho semestres lectivos. El propósito de la reformulación es promover la integración entre los cursos y departamentos, aumentar la autonomía de los estudiantes y adoptar la formación para el Sistema Único de Salud como orientación general del currículo. El nuevo currículo está dirigido para la formación de la enfermera generalista, con competencias técnicas, científicas y ético-políticas para proveer el cuidado de enfermería a individuos, familias y grupos sociales.

\section{DESCRIPTORES}

Enfermería.

Enseñanza.

Curriculum. 


\section{INTRODUÇÃO}

É com grande felicidade que celebramos os 20 anos do Departamento Enfermagem em Saúde Coletiva e 65 anos da Escola de Enfermagem. Como docente do Departamento, quero iniciar agradecendo a presença de todos nesta celebração.

À medida que vamos nos aproximando do final do evento, tenho aqui a incumbência de fechar as apresentações deste dia, apresentando a proposta de reorientação curricular desta Escola, proposta esta que acaba de ganhar novos sentidos e significados com as apresentações de minhas antecessoras, professoras Josicélia Dumet, da Universidade Federal da Bahia, e Denise Gastaldo, da Universidade de Toronto, Canadá. Sem que tivéssemos combinado, apresentaram um panorama que se dirige progressivamente do geral ao particular, até desembocar na singularidade da proposta da Escola de Enfermagem da Universidade de São Paulo (EEUSP).

\section{CONTEXTUALIZANDO O CENÁRIO DAS TRANSFORMAÇÕES NA FORMAÇÃO EM SAÚDE}

Vivemos hoje na área da formação em saúde um cenário bastante dinâmico. Na esteira das Leis de Diretrizes e Bases $(\mathrm{LDB})^{(1)}$, que dissociou diplomação e exercício profissional, muitas profissões novas estão surgindo, com inúmeras denominações que fogem das tradicionais áreas profissionalizantes. Temos o ressurgimento de algumas profissões, por exemplo, a Obstetrícia, um curso oferecido pela USP, na Escola de Artes, Ciências e Humanidades (EACH). Um outro exemplo, também na EACH, é o curso de Gerontologia. Então, é necessário fazer a leitura das possibilidades de mudança neste cenário cambiante, especialmente na área da saúde.

Parte deste cenário mais geral é o fato do Ministério da Saúde ter tomado para si a ordenação da formação da força de trabalho para o SUS, o que já estava proposto na Constituição de 1988, em seu artigo 200. Ao fazê-lo, adentrou na área da formação, uma seara tradicionalmente do Ministério da Educação e Cultura. Dessa aproximação entre os dois Ministérios resultou uma proposta pactuada para a formação em saúde que, neste momento, assume a forma de um projeto de reorientação da formação em saúde, o Pró-Saú$\mathrm{de}^{(2)}$ (Programa Nacional de Reorientação da Formação Profissional em Saúde), que os cursos de medicina e enfermagem estão vivenciando na atualidade.

No âmbito da Universidade de São Paulo, instituição de importância inconteste no cenário brasileiro e na América Latina, vivemos atualmente um momento bastante auspicioso para a graduação. Uma das metas da Pró-Reitoria de Graduação da USP é a valorização do ensino de graduação e isso se traduz na constituição de Grupos de Apoio Pedagógico (GAPs) em diversas unidades, na oferta de cursos de pedagogia universitária, voltados ao preparo para a docência universitária, e também na valorização das Licenciaturas, que foram objeto de uma proposta, iniciada na gestão anterior, de cursos de formação de professores na USP. É nesse contexto da Universidade de São Paulo que se situa a proposta de reformulação do ensino de graduação da EEUSP.

O atual currículo do curso de bacharelado em Enfermagem da Escola data de 1994. Como todos sabem, a LDB ${ }^{(1)}$ foi promulgada em 1996. AEEUSP tinha uma proposta curricular inovadora que inclusive antecedeu a $\mathrm{LDB}^{(1)}$, formulada por sua Comissão de Graduação, sob a coordenação da professora Cilene Costardi Ide pessoa de grande militância na área de educação em Enfermagem. Após dez anos, essa proposta demandava uma avaliação crítica.

Ao longo dos últimos quatro anos, a proposta de reformulação curricular ganhou densidade, especialmente a partir da constituição do Grupo de Apoio Pedagógico (GAPEEUSP), que vem realizando uma reflexão crítica sobre o ensino de enfermagem desta Escola.

\section{BASES DO PROJETO PEDAGÓGICO DAEEUSP}

Feito esse preâmbulo, passo a apresentar o que orientou a nossa reflexão na elaboração da proposta pedagógica que tivemos a oportunidade de apresentar à Escola como um todo e que, neste momento, está sendo objeto de discussão nos quatro Departamentos, para aperfeiçoamento Algumas das questões orientadoras das nossas reflexões dizem respeito, inicialmente, ao perfil do aluno que ingressa nos nossos cursos, a partir do qual construímos o perfil do aluno que desejamos formar. Quem é o ingressante no bacharelado em Enfermagem da EEUSP? Quais são suas expectativas, necessidades, valores, idéias, ideais, compromissos? Como o currículo do Curso de Graduação desta Escola pode favorecer sua formação inicial em enfermagem, considerando a totalidade humana que ele é? Como tornar possível o seu projeto de vida, que certamente inclui a dimensão da profissão e do trabalho? Qual o fio condutor para a construção de seu percurso conosco e de sua identidade profissional? Como superar os limites da relação teoria-prática, em direção a uma práxis transformadora, não apenas da formação de nossos alunos, mas de nós mesmos, docentes desta Escola, da comunidade acadêmica que, enfim, torna possível o ensino de graduação? Estes são desafios que vêm sendo discutidos pelo GAP.

Há de se considerar que a EEUSP conta atualmente com 82 docentes, dos quais 81 são doutores, configurando-se assim uma possibilidade de exercer o ensino no nível de graduação que certamente é diferenciada de muitos cursos pelo 
Brasil afora e deve traduzir-se na proposta curricular que nos propusemos a desenhar.

Face a essas questões, o papel do GAP-EEUSP é contribuir para elaboração de um projeto político-pedagógico capaz de propiciar a formação permanente de toda a comunidade acadêmica dessa Escola.

Pensamos o currículo na relação que se estabelece entre a educação e o trabalho. Todo o ensino superior no Brasil é profissionalizante, daí que o nosso ponto de partida tenha sido pensar a relação entre a formação e o futuro exercício profissional. Algumas possibilidades delineiam-se nesse cenário: desde a submissão ingênua até a adesão crítica às propostas, tanto pedagógicas como de exercício profissional.

O currículo deve expressar os compromissos que temos com a educação como um bem comum e não como mercadoria, passível, portanto, de aquisição de capital. Trata-se, em última análise, de nossos compromissos com os futuros enfermeiros e com a política pública de saúde para a população e seus princípios de acessibilidade, de universalidade, de eqüidade e integralidade.

Uma das primeiras distinções a fazer é entre o projeto político pedagógico - que dá a direcionalidade e o sentido da formação - e o currículo formal, ao qual muitas vezes nos referimos como grade, talvez porque, em certa medida e em certos momentos, ele nos aprisiona. Precisamos necessaria- mente discutir qual é o perfil de cidadão e de profissional que desejamos formar na graduação em Enfermagem desta Escola, frente a suas possibilidades e seus compromissos políticos, como parte de uma Universidade pública, com uma tradição de 65 anos. Nesse sentido, a Escola assume também a responsabilidade de defender a universidade como um bem público, como tão bem argumenta o estudo(3), e deve dar uma contribuição distinta à formação em enfermagem, porque isso produz impactos na formação de enfermeiros e enfermeiras do Brasil.

Apresentamos a seguir um esquema (Figura 1) que simboliza a discussão que temos feito acerca da formação inicial. A primeira esfera representa que a formação está mediada por saberes e práticas lastreados em conhecimentos técnicos e científicos. Essa esfera imbrica-se na formação permanente que ocorre no mundo do trabalho. Na interseção entre esses dois mundos, o da formação e o do trabalho, há o espaço das práticas, que envolve o ensino prático em campo e o estágio propriamente dito, e as condições objetivas de trabalho no SUS, com a interferência das nossas associações profissionais. No centro, onde essas várias esferas se entrecruzam, está a pessoa do estudante, alguém que virá partilhar conosco sua formação inicial - uma parte pequena da sua trajetória de formação profissional. É por essa razão que temos chamado a graduação de formação inicial dentro de um processo de formação permanente que se prolonga ao longo de toda a vida profissional.

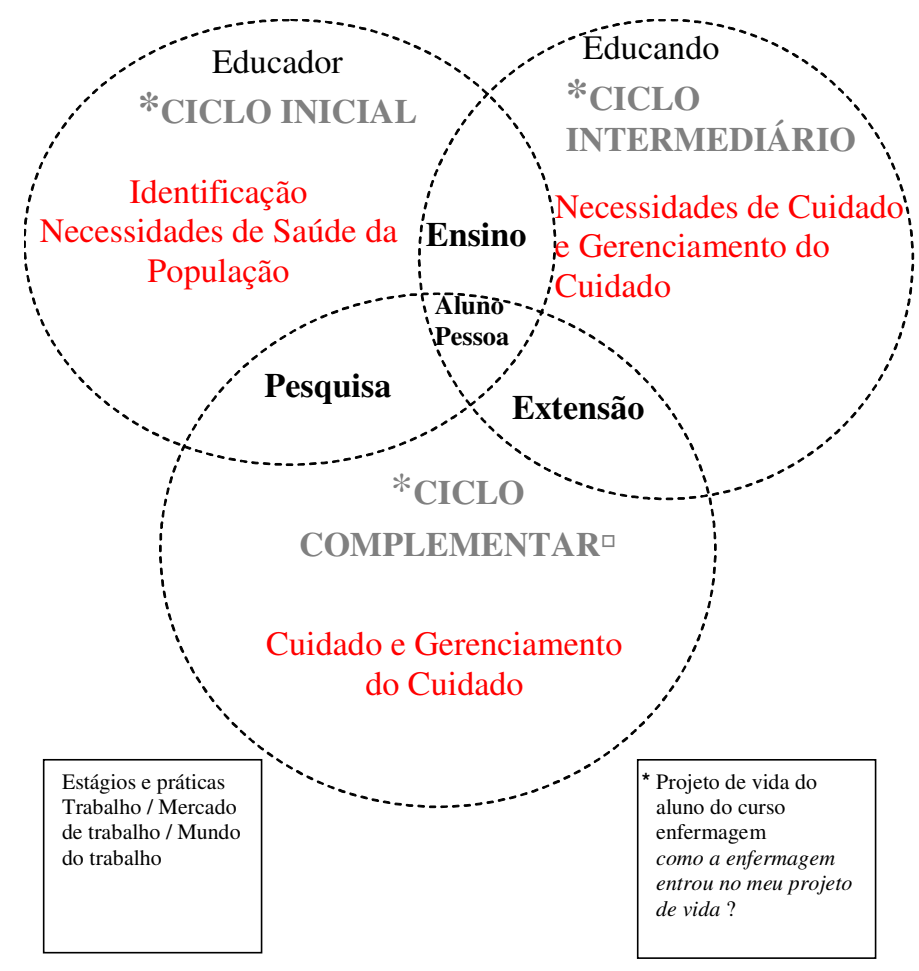

Figura 1 - Esquema representacional da estrutura curricular da EEUSP (em construção) - São Paulo - 2007 
Falar em formação inicial ao propor a reformulação do ensino de graduação tem contribuído para diminuir um pouco a nossa ansiedade. Ou seja, estamos falando dos primeiros quatro anos de uma longa trajetória profissional, em que o trabalhador da enfermagem, no caso a enfermeira, irá se reconstruindo como sujeito de suas próprias práticas ao longo de, talvez, 40 anos de exercício profissional. Enfim, o que temos como desafio é pensar como esse futuro se projeta e o que desejamos, o que é cabível, o que é possível em quatro anos de formação inicial.

Estamos falando também da relação entre educação e trabalho, num determinado contexto político, econômico, cultural, nacional e também internacional, de problemas globalizados. É dessa perspectiva comum que tentamos vislumbrar como se mostrará no futuro a formação inicial em enfermagem, quais serão seus desafios. O processo de aprendizagem, que envolve professor e aluno na aquisição de saberes e práticas necessários ao trabalho de enfermagem, não pode estar descolado desse olhar para o futuro.

É na intersecção entre educação e trabalho que se assenta a educação universitária, no caso a graduação oferecida pela Escola de Enfermagem.Trabalho aqui entendido no seu sentido mais amplo: como possibilidade de transformação da realidade natural e social, como dimensão fundamental da vida, como cultura, atividade reflexiva, fundamento do processo de elaboração e re-elaboração permanente do conhecimento.

Nesta proposta pedagógica, tomar como fundante a relação entre educação e trabalho equivale a dizer que é pelo trabalho que se dá a constituição deste sujeito social que recebe a delegação social para realizar o cuidado - a enfermeira.

O processo ensino-aprendizagem universitário envolve o professor, que é simultaneamente um pesquisador em uma universidade como a USP, que se caracteriza pela alta produção de pesquisa, e também alguém que está envolvido na extensão. $\mathrm{Na}$ Universidade, ensino, pesquisa e extensão constituem o tripé do trabalho docente. E em um outro extremo, por assim dizer, está o estudante. É na relação que se estabelece entre professor e estudante, por meio de princípios, objetivos, métodos, técnicas, instrumentos e de formatos de avaliação, que se dá o processo ensinoaprendizagem.

No movimento que estamos tentando realizar coletivamente, passamos pela análise crítica do currículo formal, sem desconhecer que, além do currículo formal, há um currículo oculto, que se faz fora dos espaços formais de ensino-aprendizagem. Passamos por um momento de desconstrução e agora estamos construindo uma proposta a ser pactuada com a comunidade acadêmica da EEUSP. Pela frente, temos a construção do projeto político-pedagógico, a discussão, a negociação e, finalmente, a pactuação de uma proposta pedagógica para o bacharelado em Enfermagem.

\section{A PROPOSTA CURRICULAR DAEEUSP}

A proposta para o bacharelado em Enfermagem da EEUSP prevê: formação generalista; currículo com quatro mil horas de duração, organizado por conteúdos, em torno de eixos; estrutura curricular organizada em ciclos, integrados por módulos, com ênfase na relação teoria-prática ${ }^{(4)}$.

O eixo central do currículo é o cuidado de enfermagem em seus diferentes sentidos, significados e dimensões. Isso porque sabemos que, mesmo entre nós, nesta Escola, não há um sentido unívoco para o que compreendemos como cuidado. A tentativa não é homogeneizar essas compreensões e concepções, mas as revelar, acreditando que é justamente na diversidade que reside a riqueza de possibilidades de construção do cuidado de enfermagem.

Entendemos que é o trabalho, e não o currículo, o definidor da formação profissional. É somente quando o estudante adentra no mundo do trabalho, na condição de trabalhador da enfermagem que, de fato, a formação profissional completa-se. Por essa razão, consideramos a prática como um lócus de geração de questões de aprendizagem. Isto quer dizer que, ao olharmos para a realidade social e para o trabalho dos profissionais de saúde nesta realidade, é que podemos pensar questões de aprendizagem. Além disso, consideramos a formação para o SUS como orientação mais geral do currículo e reconhecemos o papel social, as responsabilidades e o compromisso desta Escola, como parte de uma universidade pública.

Reconhecemos o caráter acadêmico da formação curricular, pois sabemos que estamos falando de algo que pertence ao mundo da educação, embora tenhamos como referência o mundo do trabalho. Identificamos na pesquisa uma ferramenta do processo pedagógico e do trabalho da enfermeira e pretendemos que o aprendizado do estudante seja organizado segundo os raciocínios clínico e epidemiológico, que têm extrema relevância para o trabalho profissional. Consideramos que o estudante é o sujeito do processo de formação inicial, dotado de autonomia e com participação ativa no currículo.

A estrutura curricular está organizada em três ciclos: básico, intermediário e complementar, com carga horária total de 4.000 mil horas, ministrada em oito semestres letivos, em um curso de período integral, o que equivale a 500 horas por semestre. $\mathrm{O}$ curso encerra-se com o estágio curricular, os 
dois últimos semestres do curso, como prevêem as Diretrizes Curriculares $^{(1)}$.

Em síntese, conforme mostra a Figura 1, podemos dizer que o ciclo inicial está voltado para as necessidades de saúde da população e para a identificação dessas necessidades. O ciclo intermediário, para a implementação de respostas às necessidades de cuidado e para o gerenciamento do cuidado. No ciclo complementar há um aprofundamento no cuidado e no gerenciamento, que se dará no estágio curricular supervisionado. A idéia é que nós tenhamos sempre atividades práticas, de modo a manter o vínculo com o mundo do trabalho. E, nesse processo, há o projeto de vida do estudante, que se baseia na reflexão e discussão sobre como a enfermagem entra no seu projeto de vida e como este estudante se engaja no projeto da Enfermagem para o Brasil.

O ciclo básico está estruturado em torno do eixo das necessidades, tendo como foco as bases do ensino de enfermagem que são as bases biológicas, psicossociais, epidemiológicas, clínicas, da saúde e da Enfermagem. Tem como objetivo proporcionar ao estudante uma visão abrangente e contextualizada da sociedade e do campo profissional, fornecendo instrumentos para a identificação de necessidades de saúde de indivíduos, famílias e grupos sociais.

Muitas de nossas disciplinas básicas são ministradas por outras Unidades da USP, como o Instituto de Ciências Biomédicas, os Institutos de Química e de Psicologia, o Departamento de Sociologia, dentre outros. Dentro do espírito universitário, isso é altamente desejável, mas também traz dificuldades à reconfiguração do currículo. Há ainda a questão das disciplinas optativas. Nesse ciclo inicial, estamos introduzindo uma disciplina voltada para a prática, que visa promover a integração dos conhecimentos adquiridos nas demais disciplinas.

O ciclo intermediário tem como eixo o cuidado de enfermagem, o que não quer dizer que o ensino de Enfermagem comece apenas a partir desse ciclo. Desde que o aluno ingressa na graduação em Enfermagem, no primeiro módulo do ciclo básico, já estamos falando de Enfermagem. Mas, é nesse ciclo que aprofundaremos o processo ensino-aprendizagem acerca do cuidado. Esse ciclo organiza-se em três semestres, tendo como foco os cuidados progressivos no SUS ${ }^{(5)}$.

Atualmente, organizamos o currículo em função do ciclo vital: saúde da criança, saúde da mulher, saúde do adulto, integrado com saúde coletiva e saúde mental (não necessariamente nesta ordem).

Estamos propondo reestruturar o currículo em função da forma de organização dos serviços de saúde. Queremos propiciar o desenvolvimento de conhecimentos, habilidades e atitudes para a implementação dos processos de cuidado e de gerenciamento do cuidado em diferentes cenários de prática, em especial, mas não exclusivamente, em serviços que integram a rede própria do SUS. O ciclo intermediário é constituído por três módulos, cada um com duração de um semestre letivo ou 500 horas. O primeiro módulo é o da Enfermagem na Atenção Básica, seguido por dois módulos de Enfermagem na Atenção Especializada.

E, finalmente, há o ciclo complementar, do estágio curricular propriamente dito, que tem como foco as práticas de cuidado e gerenciamento de enfermagem nos diferentes níveis de complexidade do sistema de saúde brasileiro. A carga horária desses dois últimos semestres é de 1.000 horas, sendo 800 horas dedicadas ao estágio curricular supervisionado, o que eqüivale a $20 \%$ da carga horária total do curso, conforme preconiza a LDB.

Restam 200 horas e estamos discutindo como utilizá-las dentro da proposta curricular de forma a favorecer ao máximo a autonomia do estudante na finalização do seu currículo escolar. A finalidade é desenvolver autonomia, propiciar ao estudante buscar o seu próprio conhecimento, que é uma atitude que se deve ter ao longo da vida profissional como um todo, projetar uma vida profissional com compromisso e responsabilidade, mas sem esquecer que ainda se trata da formação inicial e que há um vínculo forte com a Universidade, que se responsabiliza pelos estágios que os alunos vão realizar.

Nessa perspectiva, o estágio curricular é visto como um momento de transição e de articulação entre o mundo da formação e o mundo do trabalho, uma possibilidade de aproximar teoria e prática com vistas ao aprofundamento da compreensão desta realidade tão desafiadora em saúde. Demandará necessariamente parcerias e articulações com serviços. É um desafio complexo e deve levar em conta o projeto de lei sobre estágios, em fase de aprovação.

O objetivo do estágio curricular é promover maior aproximação com a prática profissional, integrar conhecimentos e propor projetos inovadores de assistência. E também, planejar e realizar o cuidado em vários cenários de prática, identificar tendências e perspectivas de atuação profissional, favorecer o desenvolvimento de competências para o gerenciamento do cuidado, articulando os diversos conhecimentos mobilizados ao longo da formação.

Quanto ao trabalho de conclusão de curso (TCC), a EEUSP tem uma experiência de 10 anos de elaboração de monografias de conclusão de curso e já tentamos diversas possibilidades. Hoje, atribuímos 120 horas ao trabalho de conclusão de curso. Todos os alunos são vinculados a um professor orientador a partir do $5^{\circ}$ semestre do curso. Podemos dizer que, atualmente, todo aluno da Escola de Enfermagem faz sua iniciação científica ao longo da graduação. Nem sempre com o apoio das agências de fomento, mas certamente com a orientação de um professor doutor ao longo da sua formação, o que seria desejável e também de se esperar numa Universidade como a nossa. 
Já adotamos vários formatos para o TCC. Neste momento, optamos por desvinculá-lo do estágio curricular. Quando o TCC recaía no momento do estágio curricular, algumas vezes a pesquisa tomava tal corpo que suplantava esse momento tão privilegiado de transição para a prática profissional. Ao antecipar a orientação para o $5^{\circ}$ semestre, passamos a fazer isso de maneira mais pausada, de forma que o estudante, quando chega o momento do estágio curricular, pode se dedicar a esta experiência que nós julgamos tão útil e rica para sua formação.

Na síntese dos aspectos gerais do currículo, consideramos que todo processo que se pretende transformar, por melhores possibilidades que apresentem também encerra limites. Trataremos de mostrar alguns deles, de forma breve. Temos enfrentado algumas dificuldades estruturais, em decorrência da burocracia universitária. Em relação aos campos de prática, os instrumentos de convênio são particularmente problemáticos. Imaginem, por exemplo, as estruturas jurídicas da Universidade de São Paulo e da Secretaria Municipal de Saúde de São Paulo e verão os obstáculos de todas as ordens, mas especialmente os de ordem política, que enfrentamos para formalizar um simples convênio para viabilizar o ensino de campos em serviços de saúde.

Outro desafio, que nos afeta a todos, são os processos de avaliação docente que pouco valorizam o investimento na articulação ensino-pesquisa-extensão. Vocês sabem que a régua que mede o docente não é a régua da integração docente-assistencial. A métrica é outra, que pouco valoriza o empenho e o esforço que colocamos no ensino de graduação.

Existe também a dificuldade para a operacionalização do trabalho em equipe. Vocês sabem que a Portaria 648, que trata da Política Nacional da Atenção Básica ${ }^{(6)}$, faz menção à possibilidade das enfermeiras solicitarem exames e prescre-

\section{REFERÊNCIAS}

1. Brasil. Lei n. 9.394, de 20 de dezembro de 1996. Estabelece a Lei de Diretrizes e Bases da Educação Nacional - LDB [legislação na Internet]. Brasília; 1996. [citado 2007 out. 17]. Disponível em: http://portal.mec.gov.br/arquivos/pdf/ldb.pdf

2. Brasil. Ministério da Saúde. Pró-saúde: Programa Nacional de Reorientação da Formação Profissional em Saúde. Brasília; 2005.

3. Santos BS. A universidade no século XXI: para uma reforma democrática e emancipatória da universidade. $2^{\mathrm{a}}$ ed. São Paulo: Cortez; 2005.

4. Oliveira MAC, Püschel VAA, Veríssimo MLÓ, Riesco MLG. A reforma curricular do curso de Graduação em Enfermagem da Escola de Enfermagem da Universidade de São Paulo: avanços e perspectivas. In: Resumos do $1^{\circ}$ Seminário Nacional de Diretrizes de Enfermagem na Atenção Básica em Saúde; 2007 out. 1113; Natal, BR [CD-ROM]. Natal: ABEn-Seção RN; 2007. verem medicação segundo protocolos. Conhecem também a polêmica e a crise corporativa que isso tem gerado. Ao discutir o trabalho em equipe, temos de enfrentar a força de oposição das corporações profissionais, especialmente a médica.

Além disso, há a falta de compreensão do que é ser enfermeiro generalista e a falsa oposição entre generalista e especialista, que é pouco útil ao debate sobre o perfil do egresso da formação inicial.

Há ainda inúmeros desafios e necessidades: documentar e registrar os processos de mudança que, ao mesmo tempo que são processos, são produtos; construir indicadores quantitativos e qualitativos de monitoramento desses processos, não apenas para a prática assistencial, mas para a prática docente, para os processos ensino-aprendizagem; divulgar experiências de inovação, que vão constituindo um patrimônio da Enfermagem, um acúmulo que já dispomos, em virtude do quanto a Enfermagem tem se envolvido nesses processos de mudança rumo aos princípios e diretrizes do SUS. É preciso compartilhar cada vez mais esses avanços. E, finalmente, investir na construção da eqüidade, da integralidade e da intersetorialidade.

\section{À GUISA DE CONCLUSÃO}

Reportando-me ao triângulo de Carlos Matus, cremos que, no caso desta Escola de Enfermagem, temos duas das condições essenciais para o êxito da proposta de reorientação curricular: projeto e capacidade de governo $^{(7)}$. Estamos construindo as condições de governabilidade, o que remete à singularidade de cada um dos envolvidos. É uma tarefa árdua, que tem exigido muito esforço, mas é também muito prazerosa para aqueles que valorizam o ensino da graduação na Universidade.

5. Ceccim RB, Feuerwerker LC. O quadrilátero da formação para a área da saúde: ensino, gestão, atenção e controle social. Physis Rev Saúde Coletiva. 2004;14(1):45-65.

6. Brasil. Ministério da Saúde. Secretaria de Atenção à Saúde. Departamento de Atenção Básica. Política Nacional de Atenção Básica. Brasília; 2006.

7. Kopf AW, Hortale VA. Contribuição dos sistemas de gestão de Carlos Matus para uma gestão comunicativa. Ciênc Saúde Coletiva [periódico na Internet]. 2005[citado 2007 out. 17];10 Supl: [cerca de 9 p.]. Disponível em: http://www.scielo.br/pdf/csc/ v10s0/a18v10s0.pdf 